\title{
Remarkably facile Heck and Suzuki reactions in water using a simple cationic surfactant and ligand-free palladium catalysts
}

\author{
Santanu Bhattacharya, ${ }^{a, *}$ Aasheesh Srivastava ${ }^{a}$ and Saumitra Sengupta ${ }^{b, *}$ \\ ${ }^{a}$ Department of Organic Chemistry, Indian Institute of Science, Bangalore 560 012, India \\ ${ }^{\mathrm{b}}$ Department of Chemistry, Jadavpur University, Kolkata 700 032, India
}

\begin{abstract}
A facile surfactant mediated Heck and Suzuki coupling procedure in water has been developed using ligand-free Pdcatalysts. The procedure which involves nanometric palladium colloids, is operationally simple, environmentally benign and synthetically as efficient as conventional procedures using organic solvents.
\end{abstract}

Palladium catalyzed arylation of olefins, the Heck reaction, is a powerful tool in organic synthesis. ${ }^{1}$ It has found widespread use in the synthesis of natural products, polymers, dendrimers and various conjugated architectures of materials science interest. The Heck reaction also holds much promise in many industrial processes, especially in the synthesis of fine chemicals and active pharmaceutical intermediates. ${ }^{2}$ In view of these, much attention has been paid in recent years to develop milder and operationally simpler procedures for the Heck reaction. Some important developments include the use of ligand-free Pd-catalysts in combination with tetraalkylammonium salts (Jeffery conditions), the use of palladacycles, pincer and supported palladium catalysts and more recently, the bulky electron rich phosphine and the $N$-heterocyclic carbene (NHC) ligands for palladium. ${ }^{3}$ Additives such as tetrabutylammonium bromide have led to remarkable rate enhancements in the Heck reactions of aryl iodides in organic solvents ${ }^{3 \mathrm{a}}$ whereas by using the pincer catalysts or electron rich phosphine or NHC ligands, the Heck reaction can now be carried out with the cheap, but otherwise unreactive, chloroarenes. ${ }^{3 f-j}$ Recently, Reetz et al. have shown that $\mathrm{Pd}(\mathrm{OAc})_{2}$ in combination with tetrabutylammonium bromide gives rise to nanometric Pd-colloids which are the actual catalysts under the so-called Jeffery conditions. ${ }^{4}$ Pd-nanoparticles were also shown to be involved in Heck reactions with palladacy-

\footnotetext{
* Corresponding authors. Fax: +91 33 24146266; e-mail addresses: sb@orgchem.iisc.ernet.in; jusaumitra@yahoo.co.uk
}

cles, pincers and NHC ligated catalysts and are thought to be responsible for their superior reactivity. ${ }^{5}$

However, despite all these developments on catalyst design, polar aprotic solvents $\left(\mathrm{CH}_{3} \mathrm{CN}\right.$, DMF, DMA, NMP) still remain the preferred medium for carrying out Heck reactions. Driven by environmental concerns, recently, much effort has been directed towards using water as solvent for organic and organometallic reactions. ${ }^{6}$ Although there are some reports on the Heck reaction in mixed aqueous organic solvents in the presence of PTCs or Pd-catalysts having water soluble phosphine ligands, ${ }^{6 d}$ studies directed towards the Heck reaction in water alone are less common. ${ }^{7}$ The latter are mostly confined to reactions with water soluble substrates using special additives and hence, lack a general synthetic appeal. We now report a facile surfactantmediated Heck reaction in water catalyzed by ligand-free palladium catalysts which, while being environmentally benign, rival conventional Heck reaction procedures in synthetic efficacy and operational simplicity.

As a model, the Heck reaction of PhI with methyl acrylate (MA) in water $\left(1 \% \mathrm{PdCl}_{2}, \mathrm{NaHCO}_{3}\right)$ at $80^{\circ} \mathrm{C}$ was examined under a variety of conditions (Table 1). In the absence of any surfactant, only 30\% conversion was obtained after $2 \mathrm{~h}$ (entry 1). Addition of cetyltrimethylammonium bromide (CTAB) led to a gradual increase in the conversion rate reaching a maximum of $95 \%$ after $2 \mathrm{~h}$ when $50 \mathrm{~mol} \%$ of CTAB was used (entries $2-4)$. On the other hand, the use of SDS, Brij 56 or 
Table 1. Effect of additives on the Heck reaction of $\mathrm{PhI}$ in water

\begin{tabular}{|c|c|c|}
\hline Entry & Additive ( $\mathrm{mol} \%)$ & Yield $(\%)$ \\
\hline 1 & CTAB (0) & 30 \\
\hline 2 & CTAB (7) & 50 \\
\hline 3 & CTAB (25) & 80 \\
\hline 4 & CTAB (50) & 95 \\
\hline 5 & SDS $(50)$ & 40 \\
\hline 6 & Brij 56 (50) & 30 \\
\hline 7 & $\mathrm{Bu}_{4} \mathrm{NBr}(50)$ & 50 \\
\hline
\end{tabular}

$\mathrm{Bu}_{4} \mathrm{NBr}(50 \mathrm{~mol} \%$ each) gave only marginal increases in conversion rates over those obtained in water alone (entries 5-7). It appears from these results that only cationic surfactants are capable of enhancing the rate of the Heck reaction through miceller effects. That CTAB is more efficient than $\mathrm{Bu}_{4} \mathrm{NBr}$ is also noteworthy since the latter has been shown to greatly enhance the rate of Heck reactions in conventional organic solvents. ${ }^{3 a}$

In order to understand the superiority of CTAB over other surfactant types in this aqueous Heck reaction, further physical studies were undertaken. The UV-Vis spectra of $\mathrm{PdCl}_{2}$ in water and that of a mixture of $\mathrm{PdCl}_{2}$ and $\mathrm{CTAB}$ in water at room temperature are shown in Figure 1a. The marked difference in their spectra indicates a strong interaction between $\mathrm{PdCl}_{2}$ and $\mathrm{CTAB}$ in water. Addition of MA to this mixture and heating to $80^{\circ} \mathrm{C}$ led to a color change from golden yellow to chocolate brown. The fine structures in the spectra disappeared and a new structureless band with increased intensity in the visible region appeared, indicating that Pd-nanoparticles had been formed. ${ }^{8}$ Pd-nanoparticles prepared authentically via EtOH reduction ${ }^{8 \mathrm{c}}$ of $\mathrm{PdCl}_{2}$ showed an identical structureless UV-Vis band (Fig. 1a). Notably, addition of $\mathrm{PhI}$ to the mixture of $\mathrm{PdCl}_{2}$ and $\mathrm{CTAB}$ in water and heating to $80^{\circ} \mathrm{C}$ did not lead to any color change or any difference in the UV-Vis spectra (not shown). These results clearly showed that MA acted as the reducing agent for $\mathrm{PdCl}_{2}$ to produce the CTAB-stabilized Pd-nanoparticles. A transmission electron microscopic (TEM) image clearly indicated

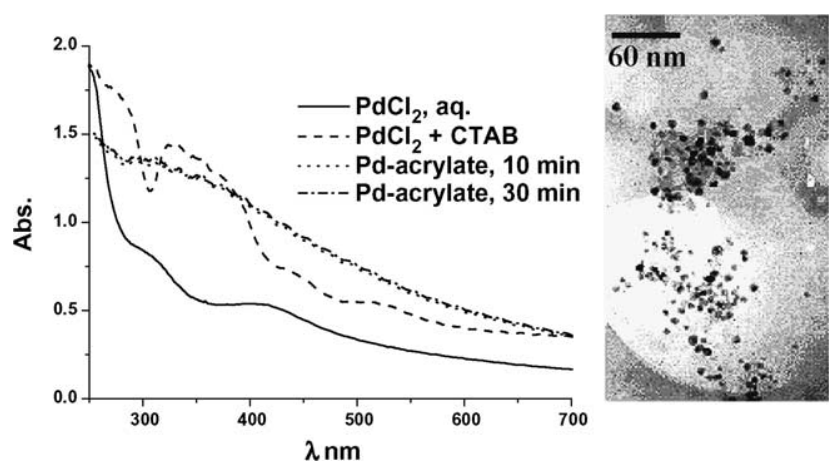

Figure 1. (a) UV-Vis changes during Pd-nanoparticle formation in water with MA and CTAB; (b) TEM image of the Pd-nanoparticles formed. the formation of Pd-nanoparticles having an average diameter of $5 \mathrm{~nm}$ (Fig. 1b).

In a control experiment, the reaction components without CTAB were heated in water at $80^{\circ} \mathrm{C}$ for $2 \mathrm{~h}$ which gave a nearly clear solution with some Pd-black formation $(30 \%$ conversion, cf. entry 1 , Table 1$)$. Addition of CTAB (50 mol \%) immediately led to the formation of a brown black emulsion attesting to the stabilizing role of CTAB towards Pd-nanocluster formation. Further heating at $80^{\circ} \mathrm{C}$ for $2 \mathrm{~h}$ produced methyl cinnamate in $67 \%$ yield. Thus, CTAB performs a dual role in these aqueous Heck reactions. First, it provides a strong miceller effect and second, it acts as a stabilizer for Pdnanocluster formation. ${ }^{9}$ Perhaps, SDS and Brij 56 are not capable of stabilizing Pd-nanoclusters under the above conditions and $\mathrm{Bu}_{4} \mathrm{NBr}$, while being able to stabilize Pd-nanoparticles, ${ }^{4 c, 9}$ cannot provide a miceller effect to the extent CTAB is capable of, thus explaining the decisive advantage of using $\mathrm{CTAB}$ over the other additives in these aqueous Heck reactions. Organic reactants are usually partitioned into micelles by hydrophobic interactions. $\mathrm{CTAB}$ with its $\mathrm{C}_{16}$-hydrocarbon chain provides a strong hydrophobic force that can solubilize the organic reactants much more efficiently than $\mathrm{Bu}_{4} \mathrm{NBr}$ can do with its shorter $\mathrm{C}_{4}$-chains. The rate enhancing micellar effect may be due to the increased localization of the reactants in micelles together with the typical physicochemical properties of its environment which are significantly different from those of the bulk solvents. ${ }^{10}$

The synthetic efficacy of this surfactant mediated aqueous Heck reaction was then studied with a number of different aryl halides and olefins (Scheme 1) and the results shown in Table 2. Heck reaction of iodobenzene (1a) with MA, styrene and acrylonitrile gave good yields of the corresponding products 2a-c within $2-3 \mathrm{~h}$ at $80^{\circ} \mathrm{C}$ (entries $\left.1-3\right)$. $\mathrm{Pd}(\mathrm{OAc})_{2}$ can also be used as a catalyst in these reactions with equal efficacy. A lower catalytic loading $\left(0.1 \% \mathrm{PdCl}_{2}\right)$ can be used with no loss in product yield (entry 2). As expected, iodoarenes with an ortho-substituent (1b) or an electron donating substituent (1c) considerably lowered the reaction rate. In these cases, a full equivalent of CTAB, a higher temperature $\left(100^{\circ} \mathrm{C}\right)$ and prolonged reaction times were required to obtain good yields of the products $2 \mathbf{2 d - f}$ (entries 4-6). $\mathrm{NaOAc}$ was found to be a superior base over $\mathrm{NaHCO}_{3}$ for these latter reactions. Nevertheless, the reaction times and product yields are comparable, if not better, than those reported in organic solvents under conventional Heck reaction conditions. Less reactive bromoarenes such as 1d required an even higher reac-

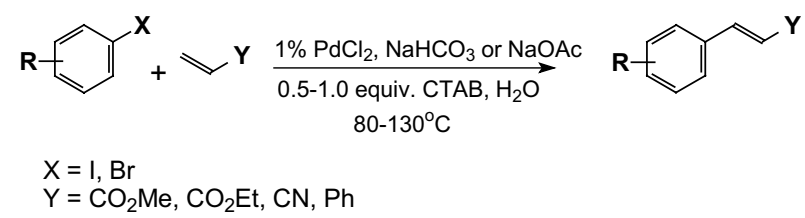

Scheme 1. 
Table 2. CTAB-mediated Heck Reaction in water ${ }^{\mathrm{a}}$

Entry

a $1 \mathrm{mmol} \mathrm{ArX,} 2 \mathrm{mmol}$ olefin, $0.5 \mathrm{mmol} \mathrm{CTAB}, 2 \mathrm{mmol} \mathrm{NaHCO}$ and $0.01 \mathrm{mmol}$ of $\mathrm{PdCl}_{2}$ in water $(3 \mathrm{~mL})$.

${ }^{\mathrm{b}} 1$ equiv $\mathrm{CTAB}$ and 2 equiv $\mathrm{NaOAc}$ were used. $\mathrm{MA}=$ methyl acrylate, $\mathrm{S}=$ styrene, $\mathrm{AN}=$ acrylonitrile, $\mathrm{EA}=$ ethyl acrylate.

tion temperature $\left(130^{\circ} \mathrm{C}\right)$, the corresponding Heck product $\mathbf{2 g}$ being obtained in $80 \%$ yield after $12 \mathrm{~h}$ (entry 7). It may be noted that even in traditional organic solvents, the Heck reactions of bromoarenes usually require higher reaction temperatures (ca. 130$\left.140{ }^{\circ} \mathrm{C}\right)^{4 \mathrm{~d}, 5 \mathrm{c}}$ and hence, our aqueous Heck reaction protocol compares favorably with conventional conditions. Notably, in contrast to the findings of Reetz and de Vries, ${ }^{4 \mathrm{~d}}$ lowering of the Pd-loading $\left(0.1 \% \mathrm{PdCl}_{2}\right.$ or $\left.\mathrm{Pd}(\mathrm{OAc})_{2}\right)$ did not improve the Heck reaction profile of the bromoarene 1d.

The Suzuki cross coupling reaction is a powerful Pd-catalyzed regime for the synthesis of unsymmetrical biaryls from aryl boronic acids and haloarenes. ${ }^{11} \mathrm{Pd}$-nanoparticle catalyzed Suzuki coupling in organic solvents has also been described. ${ }^{4 a, d, 12}$ However, there are no reports on Suzuki coupling reactions with ligand-free Pd-catalysts in water alone, except for one example that involved high reaction temperatures $\left(>150^{\circ} \mathrm{C}\right)$ under microwave irradiation. ${ }^{13}$ The above success with the Heck reaction in water prompted us to explore such a possibility. In the event, $\mathrm{PhB}(\mathrm{OH})_{2} 3$ was smoothly coupled with haloarenes 1c,d in water in the presence of $\mathrm{CTAB}$ and $1 \% \mathrm{Pd}(\mathrm{OAc})_{2}$ at $100{ }^{\circ} \mathrm{C}$ to give the biaryls 4a,b in excellent yields (Scheme 2). The reactions are remarkably fast (1-3 h) with high turnover frequencies.

In conclusion, a CTAB-mediated aqueous Heck and Suzuki coupling procedure has been developed using

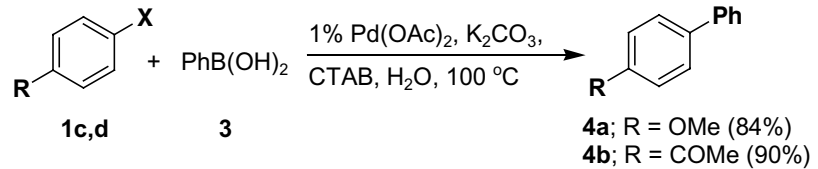

Scheme 2. ligand-free Pd-catalysts. ${ }^{14}$ The procedure is operationally simple, environmentally benign and is comparable, if not better, in synthetic efficacy to conventional Pd-catalyzed coupling protocols in organic solvents. The use of an aqueous reaction medium and colloidal Pd-catalysts promise further opportunities in batch processing and catalyst recycling. ${ }^{15}$

\section{Acknowledgements}

A.S. acknowledges CSIR, New Delhi for a Senior Research Fellowship. S.S. thanks the Department of Organic Chemistry, Indian Institute of Science, Bangalore for an OC-ICOS Visiting Fellowship.

\section{References and notes}

1. (a) Heck, R. F. Palladium Reagents in Organic Synthesis; Academic Press: London, 1985; (b) de Meijere, A.; Meier, F. Angew. Chem., Int. Ed. Engl. 1994, 33, 2379; (c) Bräse, S.; de Meijere, A.. In Metal-Catalyzed Cross-Coupling Reactions; Diederich, F., Stang, P. J., Eds.; Wiley-VCH: Weinheim, 1998, p 99; (d) Beletskaya, I. P.; Cheprakov, A. V. Chem. Rev. 2000, 100, 3009; (e) Whitcombe, N. J.; Hii, K. K.; Gibson, S. E. Tetrahedron 2001, 57, 7449; (f) Farina, V. Adv. Synth. Catal. 2004, 346, 1553.

2. (a) de Vries, J. G. Can. J. Chem. 2001, 79, 1086; (b) Blaser, H.-U.; Indolese, A.; Schnyder, A.; Steiner, H.; Studer, M. J. Mol. Catal. A: Chem. 2001, 173, 3; (c) Tucker, C. E.; de Vries, J. G. Topics in Catalysis 2002, 19, 111; (d) de Vries, J. G.; de Vries, A. H. M. Eur. J. Org. Chem. 2003, 799; (e) Blaser, H.-U.; Indolese, A.; Naud, F.; Nettekoven, U.; Schnyder, A. Adv. Synth. Catal. 2004, 346, 1583.

3. (a) Jeffery, T. In Advances in Metal-Organic Chemistry; Liebeskind, L. S., Ed.; JAI Press: Greenwich, 1996; Vol. 5, p 153; (b) Böhm, V. P. W.; Herrmann, W. A. Chem. Eur. 
J. 2000, 6, 1017; (c) Dupont, J.; Pfeffer, M.; Spencer, J. Eur. J. Inorg. Chem. 2001, 1917; (d) Biffis, A.; Zecca, M.; Basato, M. J. Mol. Catal. A: Chem. 2001, 173, 249; (e) Köhler, K.; Heidenreich, R. G.; Krauter, J. G. E.; Pietsch, J. Chem. Eur. J. 2002, 8, 622; (f) Herrmann, W. A. Angew. Chem., Int. Ed. 2002, 41, 1290; (g) Littke, A. F.; Fu, G. C. Angew. Chem., Int. Ed. 2002, 41, 4176; (h) van der Boom, M. E.; Milstein, D. Chem. Rev. 2003, 103, 1759; (i) Bedford, R. B. Chem. Commun. 2003, 1787; (j) Beletskaya, I. P.; Cheprakov, A. V. J. Organomet. Chem. 2004, 689, 4055; (k) Peris, E.; Crabtree, R. H. Coord. Chem. Rev. 2004, 248, 2239; (1) Christmann, U.; Vilar, R. Angew. Chem., Int. Ed. 2005, 44, 366.

4. (a) Reetz, M. T.; Breinbauer, R.; Wanninger, K. Tetrahedron Lett. 1996, 37, 4499; (b) Beller, M.; Fischer, H.; Kühlein, K.; Reisinger, C.-P.; Herrmann, W. A. $J$. Organomet. Chem. 1996, 520, 257; (c) Reetz, M. T.; Westermann, E. Angew. Chem., Int. Ed. 2000, 39, 165; (d) Reetz, M. T.; de Vries, J. G. Chem. Commun. 2004, 1559.

5. (a) Deshmukh, R. R.; Rajagopal, R.; Srinivasan, K. V. Chem. Commun. 2001, 1544; (b) de Vries, A. H. M.; Mulders, J. M. C. A.; Mommers, J. H. M.; Henderickx, H. J. W.; de Vries, J. G. Org. Lett. 2003, 5, 3285; (c) Eberhard, M. R. Org. Lett. 2004, 6, 2125.

6. (a) Li, C.-H.; Chan, T.-H. Organic Reactions in Aqueous Media; John Wiley \& Sons: New York, 1997; (b) Cornils, B.; Herrmann, W. A. Aqueous Phase Organometallic Chemistry: Concepts and Applications; Wiley-VCH: Weinheim, 1998; (c) Organic Synthesis in Water; Grieco, P. A., Ed.; Blackie Academic \& Professional: London, 1998; (d) Genet, J.-P.; Savignac, M. J. Organomet. Chem. 1999, 576, 305; (e) Joo, F. Aqueous Organometallic Catalysis; Kluwer: Dordrecht, 2001.

7. (a) Bumagin, N. A.; More, P. G.; Beletskaya, I. P. J. Organomet. Chem. 1989, 364, 231; (b) Bumagin, N. A.; Bykov, V. V.; Sukhomlinova, L. I.; Tolstaya, T. P.; Beletskaya, I. P. J. Organomet. Chem. 1995, 486, 259; (c) Jeffery, T. Tetrahedron 1996, 52, 10113; (d) Mukhopadhyay, S.; Rothenburg, G.; Joshi, A.; Baidossi, M.; Sasson, Y. Adv. Synth. Catal. 2002, 344, 348; (e) Yamada, Y. M. A.; Takeda, K.; Takahashi, H.; Ikegami, S. Tetrahedron 2004, 60, 4059 .

8. (a) Teranishi, T.; Miyake, M. Chem. Mater. 1998, 10, 594; (b) Ohde, H.; Wai, C. M.; Kim, H.; Kim, J.; Odhe, M.
J. Am. Chem. Soc. 2002, 124, 4540; (c) Scott, R. W. J.; Ye, H.; Henriquez, R. R.; Crooks, R. M. Chem. Mater. 2003, 15,3873 .

9. (a) Tetraalkylammonium salts are known to stabilize Pdnanoclusters: Reetz, M. T.; Maase, M. Adv. Mater. 1999, 11, 773; (b) Reetz, M. T.; Winter, M.; Breinbauer, R.; Thurn-Albrecht, T.; Vogel, W. Chem. Eur. J. 2001, 7, 1084.

10. Bhattacharya, S.; Praveen Kumar, V. J. Org. Chem. 2004, 69, 559.

11. (a) Miyaura, N.; Suzuki, A. Chem. Rev. 1995, 95, 2457; (b) Suzuki, A. In Metal-Catalyzed Cross-Coupling Reactions; Diederich, F., Stang, P. J., Eds.; Wiley-VCH: Weinheim, 1998, p 49; (c) Hassan, J.; Sevignon, M.; Gozzi, C.; Schulz, E.; Lemaire, M. Chem. Rev. 2002, 102, 1359; (d) Kotha, S.; Lahiri, K.; Kashinath, D. Tetrahedron 2002, 58, 9633.

12. (a) Kogan, V.; Aizenshtat, Z.; Popovitz-Biro, R.; Neumann, R. Org. Lett. 2002, 4, 3529; (b) Mori, K.; Yamaguchi, K.; Hara, T.; Mizugaki, T.; Ebitani, K.; Kaneda, K. J. Am. Chem. Soc. 2002, 124, 11572; (c) Narayanan, R.; El-Sayed, M. A. J. Am. Chem. Soc. 2003, 125,8340 .

13. Leadbeater, N. E.; Marco, M. Org. Lett. 2002, 4, 2973.

14. General procedure for the CTAB-mediated Heck reaction in water: A hard glass pressure tube $(25 \mathrm{~mL})$ with a Teflon screw cap was charged with the aryl halide 1a-d $(1.0 \mathrm{mmol})$, olefin $(2.0 \mathrm{mmol}), \mathrm{CTAB}(0.5 \mathrm{mmol}$ for $\mathbf{1 a}$; $1.0 \mathrm{mmol}$ for $\mathbf{1 b}-\mathbf{d}), \mathrm{PdCl}_{2} \quad(0.01 \mathrm{mmol}), \mathrm{NaHCO}_{3}$ $(2.0 \mathrm{mmol}$ for 1a) or NaOAc $(2.0 \mathrm{mmol}$ for $\mathbf{1 b}-\mathbf{d})$ in water $(3 \mathrm{~mL})$. The mixture was then heated with vigorous stirring at the temperature and for the time shown in Table 2. It was then cooled, diluted with water and extracted with ethyl acetate. The products $\mathbf{2} \mathbf{a}-\mathbf{g}$ were purified by column chromatography over silica gel.

15. (a) de Vries, A. H. M.; Parlevliet, F. J.; Schmieder-van de Vondervoot, L.; Mommers, J. H. M.; Henderickx, H. J. W.; Walet, M. A. M.; de Vries, J. G. Adv. Synth. Catal. 2002, 344, 996; (b) Chandrasekhar, S.; Narsihmulu, Ch.; Sultana, S. S.; Reddy, N. R. Org. Lett. 2002, 4, 4399; (c) Liu, S.; Fukuyama, T.; Sato, M.; Ryu, I. Org. Process Res. Dev. 2004, 8, 477; (d) Nobre, S. M.; Wolke, S. I.; da Rosa, R. G.; Monteiro, A. L. Tetrahedron Lett. 2004, 45, 6527. 